\title{
TRAVESSIAS URBANAS: A FOTOGRAFIA DOS ESPAÇOS VAZIOS E NÃO-LUGARES
}

Pablo Quaglia Rodrigues ${ }^{1}$

Vivemos hoje inseridos em um sistema de interrelações sociais. A paisagem urbana é resultado da ação do homem, não como individuo, mas como sociedade, dentro da qual existem algumas modificações ocorridas no espaço urbano que possibilitam a especulação imobiliária e resultam na distribuição demográfica, ou morfologia urbana. A partir dessa lógica, a cidade é composta por áreas densamente ocupadas onde, eventualmente, estarão presentes também os definidos vazios urbanos.

O dinamismo das cidades é resultado de uma junção entre diferentes formas de apropriação; é o contraste entre cheio e vazio. Lotes vagos, prédios abandonados, casas demolidas para compor o processo de verticalização e adensamento e a ausência de caminhantes nas ruas, são elementos que podem definir os vazios urbanos. Segundo Nelson Brissac Peixoto (1996), eles provocam rearticulações no desenho da cidade, pela conexão de elementos afastados. Sendo assim, toda experiência urbana implica ruptura, distância, tentativa de articulação de um espaço fragmentado, através das intransponíveis descontinuidades entre suas partes.

O tempo imposto para a vida urbana, relacionado ao sistema capitalista, não permite a observação das cidades. O cotidiano e o circunstancial observado pelo Flâneur de Baudelaire foram reduzidos devido à velocidade dos meios de comunicação e transporte. A urbanização modernista, mais preocupada com os automóveis do que com os pedestres, acelerou as passagens entre os espaços de permanência. $O$ trânsito entre estes espaços, sem que haja relação entre as pessoas, faz com que o sujeito perca sua identidade. O etnólogo Marc Augé (1994) analisa alguns espaços como não-lugares, onde o lugar de passagem é incapaz de formar identidade e relacionamentos. Os nãolugares são percorridos por pessoas em trânsito, são os aeroportos, supermercados, vias-expressas e outras estruturas que caracterizam as cidades atuais.

Pensando nesses contrastes existentes nas cidades, esse texto propõe uma discussão sobre as paisagens urbanas contemporâneas, trazendo a relação entre vazios urbanos e não-lugares por meio da fotografia. Assim como foi necessário um olhar cartógrafo para percorrer esses espaços, foi necessária uma travessia pela conceituação dos temas abordados para que os elementos poéticos possam dialogar com o teórico, permeado pela fotografia durante o movimento deste trabalho; é um olhar da estética/poética contemporânea sobre a paisagem urbana.

\section{História do vazio em Belo Horizonte}

A ideia de mudar a capital inicialmente localizada na cidade de Ouro Preto era a intenção não apenas do século passado. No ano de 1879 já houvera uma tentativa de transferir a capital de Minas Gerais para outra localidade, sendo proposta pelos inconfidentes a cidade de São João delRei. Mas, foi apenas após a Proclamação da República que surgiu a ideia de levar a nova capital a uma cidade então planejada, uma cidade a ser construída.

Iniciada a partir de um projeto de Aarão Reis, a cidade era dividida em três zonas: urbana, suburbana e rural. Esse planejamento norteou o crescimento e as características físicas da cidade. A zona urbana foi bem definida, delimitada pela Avenida do Contorno,

\footnotetext{
${ }^{1}$ Formado em Educação Artística com habilitação em Artes plásticas pela Escola Guignard - UEMG e mestrando em Educação pela UFSJ.
} 
onde internamente se desenvolve uma forma retilínea. Fora deste limite, ocorreu um traçado orgânico, sem tamanha rigidez.

O traçado reticulado dentro do perímetro urbano foi composto pela sobreposição de duas malhas quadriculadas. Uma destas resultou em quarteirões de aproximadamente 120 metros de comprimento e largura e a outra, mais aberta, compõe as grandes avenidas sobreposta em $45^{\circ}$, resultando em quarteirões triangulares. Vale ressaltar que o projeto de Aarão Reis ignorou a natureza do espaço existente: a topografia, nascentes, córregos e rios. Em consequência ao planejamento implantado, a cidade lida atualmente com problemas ambientais.

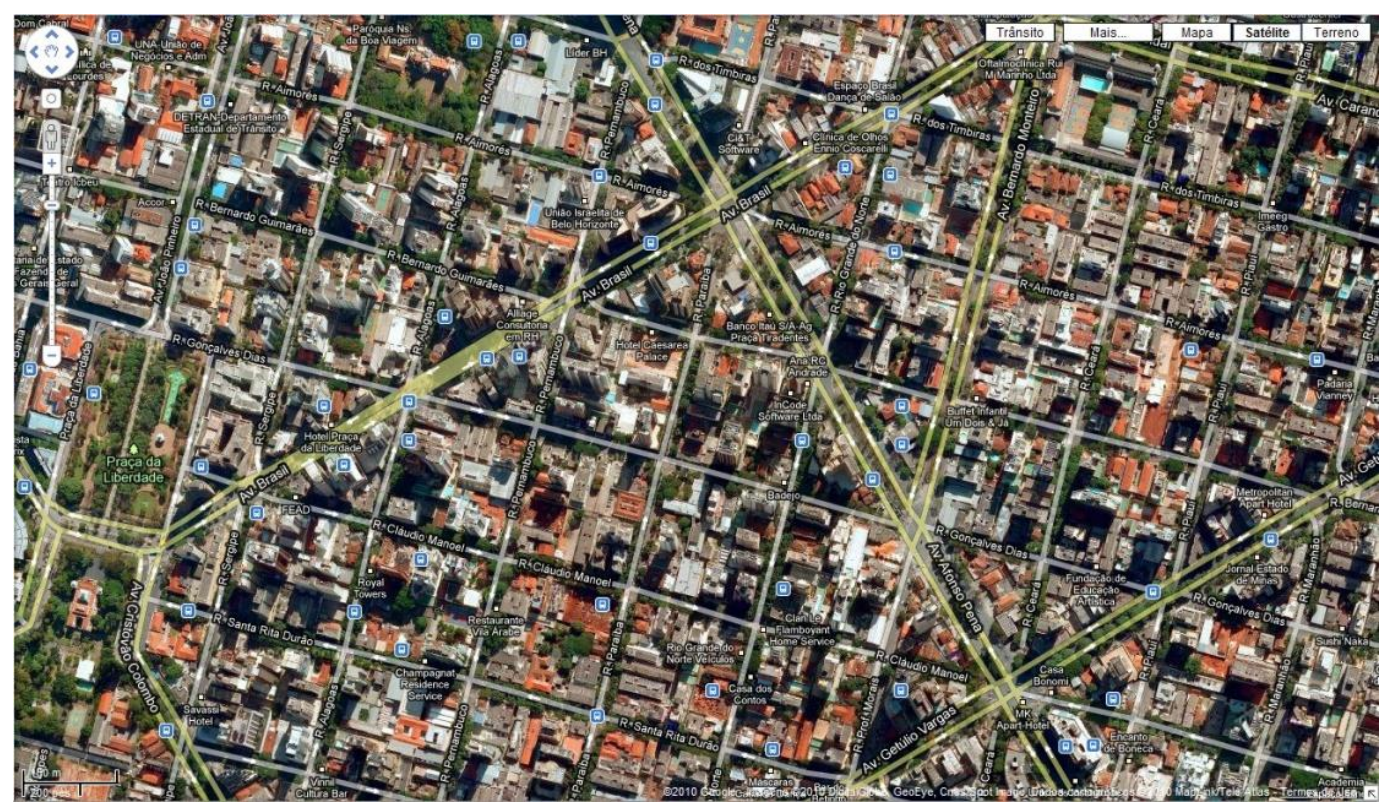

Fig. 1: Vista aérea de Belo Horizonte - Fonte: 〈http://maps.google.com.br/> (acesso em: 05/04/2010)

Marcada pela constante modificação de sua paisagem, cada vez mais adensada, a cidade se expandiu para a zona suburbana antes mesmo de ocorrer a saturação do Centro. Essa ocupação rarefeita do espaço da cidade resultou numa imagem efêmera (em obras). Carlos Teixeira (1999, p. 120) conta que "a cidade correu para as áreas onde as carências eram maiores, iniciando um processo que iria repetir-se sempre na sua historia: infraestrutura no centro, habitantes na periferia.".

Ainda que a cidade tenha seu crescimento direcionado para além da área central, a Avenida Afonso Pena foi criada com intuito de transformar o Centro em uma passagem obrigatória da cidade. A Avenida do Contorno, que delimita a zona urbana, foi pensada como via de relação social e circulação de bens: "zona de negociação, das inter-relações de poder, de identidade, de sedução e de destruição”. (TEIXEIRA, 1999, p. 78)

Com a centralidade proposta, Aarão Reis esperava que o crescimento acontecesse no sentido cidade-periferia, o que não ocorreu. Devido ao êxodo de pessoas em busca de oportunidades na cidade grande e a atração da população pelo vazio, a zona suburbana foi crescendo desordenadamente. Com o adensamento da periferia e a necessidade de utilizar o Centro para ligar a outras partes da cidade, este, com o passar dos anos, foi se enchendo até suas vias não suportarem a quantidade de veículos que ali circulavam. O centro ficou saturado devido à convergência de carros e ônibus que chegavam de todos os bairros, o que o tornou impróprio para exercer as funções que lhe foram propostas no projeto. 
O Centro passa então a ser o lugar de onde escapa tudo que é bom: o melhor comercio, os melhores serviços, o conforto, o dinheiro que gera investimentos e empregos - e para onde converge tudo o que é ruim - a desordem, a marginalidade, a decadência.(TEIXEIRA, 1999, p. 125)

A decadência da área central gerou na zona suburbana a "construção" de várias "centralidades", que começaram a exercer as atividades que o Centro não estava mais apto a exercer. Essa descentralização fez com que os espaços públicos ficassem inóspitos, e com isso, iniciaram-se as construções de espaços semiprivados, semipermeáveis e semipúblicos. As praças perderam parte de seu potencial de sociabilidade e surgiram os shoppings center, exemplo claro da incerta relação público-privado e ocupantes de vazios presentes na paisagem.

Presente em toda história de Belo Horizonte, o vazio, tratado por Carlos Teixeira (1999) como o não adensamento, pode ser revelado não apenas como possibilidades de crescimento. $\mathrm{O}$ vazio era também observado anteriormente à construção da nova capital. Começava com "montanhas e o vazio da vegetação do cerrado"2 e passou hoje a fazer parte, assim como as edificações, da paisagem urbana. "(...) um dia preservando os vazios, no outro saturando a cidade com mais e mais arquitetura." 3

\title{
O que seriam "não-lugares", “vazios urbanos" e "resíduos urbanos"?
}

A descrição e discussão dos estudos já realizados que vem por ventura revelar formas diferentes da produção dos vazios nas cidades é de extrema importância. Esta análise possibilita extrair de forma precisa as possibilidades de produção fotográfica e crítica sobre as "Travessias Urbanas". A começar do termo "não-lugares" do etnólogo Marc Augé (1994), passando pela discussão pouco disseminada de "vazios urbanos" e, por fim, refletir sobre o termo "resíduos urbanos".

\section{Não-Lugares}

\begin{abstract}
Os não-lugares são tanto as instalações necessárias à circulação acelerada das pessoas e bens (vias expressas, trevos rodoviários, aeroportos) quanto os próprios meios de transporte ou os grandes centros comerciais, ou ainda os campos de transito prolongado onde são estacionados os refugiados do planeta.(AUGÉ, 1994, p. 36)
\end{abstract}

O modelo urbanístico modernista, com os olhos voltados para os automóveis, contribuiu muito para a não apropriação dos espaços públicos. Uma vez que o transeunte circula pela cidade sem a preocupação do que está no seu entorno, a sua percepção do espaço é vaga. A velocidade proporcionada pelas áreas de circulação da cidade (ruas e, sobretudo avenidas) e pelo cotidiano, contribuiu para que a relação indivíduo-cidade fosse reduzida a passagens. A travessia casa-trabalho não foi observado como um espaço de possível apropriação, ele foi considerado apenas como uma ponte de ligação entre os espaços de permanência, onde a atenção do indivíduo não estava voltada para o mesmo. Espaços de permanência são aqueles onde o indivíduo exerce alguma função do seu cotidiano. Temos como exemplo a residência e o trabalho. São espaços onde o indivíduo tem identidade, onde há relação social e onde ele cria uma relação histórica com esse ambiente. Este necessita

\footnotetext{
${ }^{2}$ TEIXEIRA, 1999, p. 275.

${ }^{3}$ IBIDEM, p. 271.
} 
ser vivido e atentado para então proporcionar a convivência entre indivíduos e se revelar como uma paisagem também de contemplação.

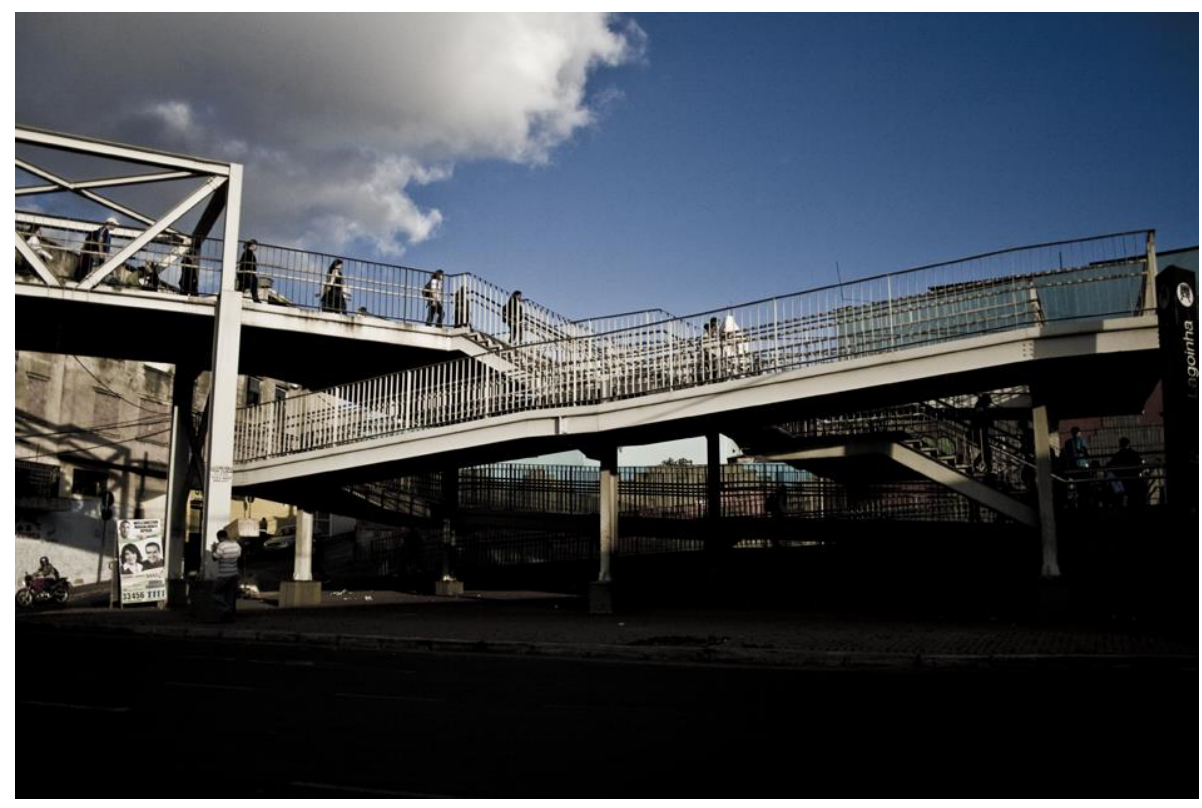

Fig. 2: Passarela. Fonte: Coleção do autor

O etnólogo Marc Augé (1994) em "Não-Lugares" cita transformações sociais: a primeira é devida à forma que o tempo é compreendido. Devido à velocidade factual na contemporaneidade, os acontecimentos se tornam história logo que ocorridos: o ontem já é história. Dessa forma, os ocorridos, sendo eles de grande importância ou não, são facilmente esquecidos e relevados. Não é possível aprender com uma história (o ontem já é historia) que não foi devidamente compreendida e interiorizada devido à velocidade dos fatos. Fatores como a superabundância dos fatos associados à velocidade das informações e à falta de relação "sistema-mundo" são possibilitados pelos avanços tecnológicos e se constituem em um problema para os historiadores.

A segunda transformação diz respeito ao espaço junto ao avanço tecnológico. Fotos aéreas entre outras formas de divulgação de imagens carregadas de significados fazem com que o mundo se abra, e leva ao individuo a consciência da amplidão daquilo que o cerca. A tecnologia contribuiu também para que essa percepção do espaço fosse reduzida. O enorme fluxo das informações e imagens, muitas vezes manipuladas pelos meios de comunicação e os novos meios de transporte, que em poucas horas possibilitam o deslocamento de uma capital a outra, são exemplos que passam a sensação de redução dos espaços "vazios".

A constante mudança espacial nas concentrações urbanas e migrações populacionais multiplicaram os vazios, chamados de não-lugares: grandes avenidas, aeroporto, rodovias. São espaços de ligação, que tem como objetivo a redução do tempo entre os espaços de permanência.

A individualização cada vez mais interiorizada na população constituiu a terceira transformação. Os fatores acima citados enfraqueceram as referências coletivas fazendo com que se criasse uma necessidade de dar um sentido ao presente, provocando um individualismo exacerbado, porém, sem identidade.

Augé (1994) utilizou-se de vários teóricos para a definição de lugar comum, como a do antropólogo Marcel Mauss (1966), onde a noção sociológica de lugar é "aquela de cultura localizada no tempo e no espaço" (p. 36). Um exemplo que o autor usou é da tribo indígena: os índios têm uma cultura, uma história relacionada com aquele espaço, espaço no qual se relacionam. 
O lugar antropológico é antes de tudo um lugar geométrico, "trata-se da linha, da interseção das linhas e do ponto de interseção" (AUGÈ, 1994, p. 36) ${ }^{4}$. Na geografia, o lugar antropológico se refere aos caminhos, aos itinerários que as pessoas passam em seu cotidiano, às praças, calçadas... os mercados, igrejas, monumentos também fazem parte dessa lógica, uma vez que pessoas passam determinado tempo se relacionando com outros e com os espaços.

Essas questões geográficas se encontram no momento em que se percorre um itinerário, atravessa por diversos cruzamentos, monumentos e mercados. Os itinerários passam por pontos notáveis que constituem aglomerações espaciais: lojas, praças e monumentos. Esses ajuntamentos criam centros de atração durante o percurso. $\mathrm{O}$ transeunte passa por diversos centros e geralmente estes são marcados por locais de mercados e convivência.

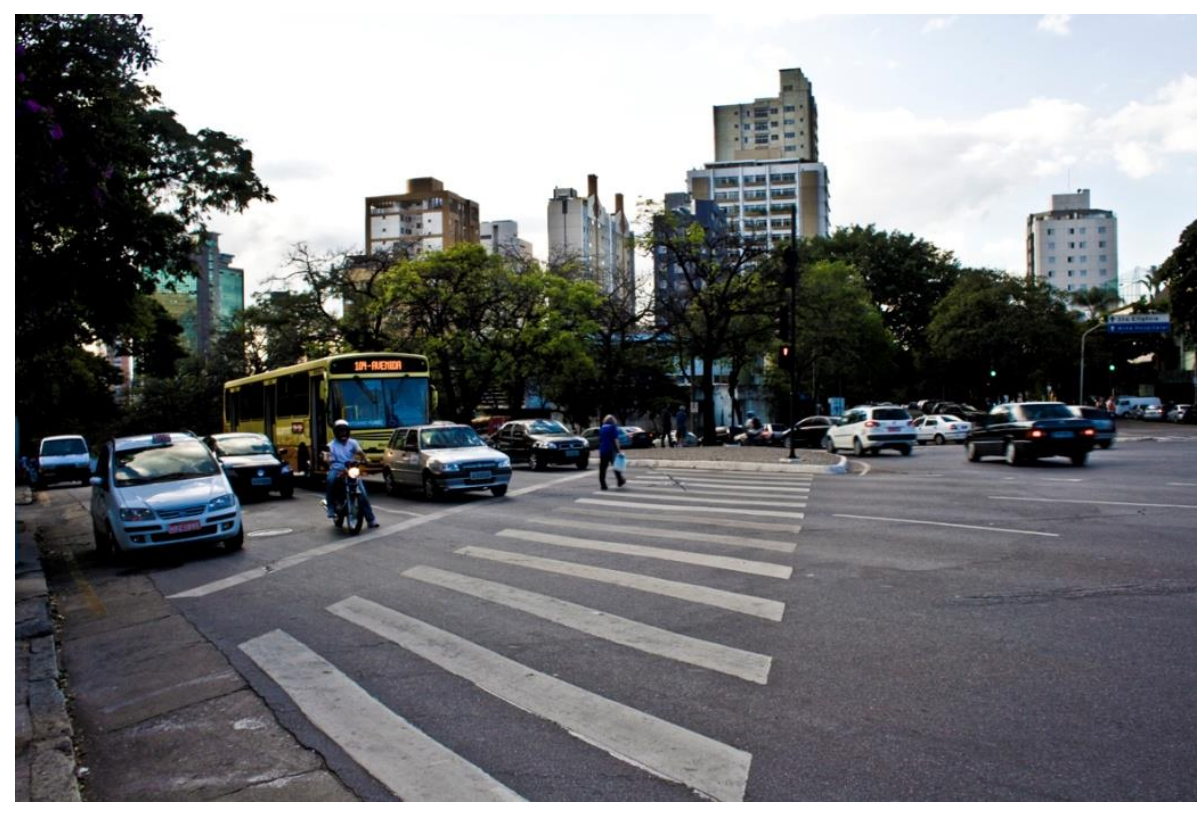

Fig. 3: Av. Afonso Pena. Fonte: Coleção do autor

Com o advento da modernidade, o tempo de flanar (Etimologia: voc. consid. gal. pelos puristas, que sugeriram em seu lugar: vaguear, perambular ociosamente) foi perdendo força (HOUAISS, 2001). Com a grande expansão urbana, os polos de mercados espalhados pela cidade e a velocidade que o cotidiano impõe dificultam o relacionamento interpessoal. A relação entre as pessoas e o espaço resulta na utilização das vias somente como passagens, ignorando as construções que as cercam e até mesmo os nomes das ruas que fazem parte do seu itinerário.

O lugar perde sua função quando, no deslocamento, o viajante tem apenas visões parciais, momentâneas da ambiência do trajeto. Um turista se contenta apenas com informações e com suas fotografias dos pontos turísticos, não estabelecendo assim a relação histórica com o lugar. Esses indivíduos, de espectadores passam a ser o próprio espetáculo, o foco principal de uma fotografia que tem como plano de fundo um ponto turístico.

O termo não-lugares se relaciona com duas realidades distintas que se completam: a dos espaços (vias, parques, praças, comércio) e a da relação que se estabelece neles. O vínculo existente entre o espaço e a relação só reforça o sentido de não-lugares, quando ocorre uma relação direcionada ou quando ocorre para objetivar seus fins. A relação do indivíduo com o não-lugar passa por palavras, imagens e textos. Esses signos reforçam a individualização. São

\footnotetext{
${ }^{4}$ IBIDEM, p. 55.
} 
eles que ditam como se deve proceder em determinados locais ou em que direção se deve seguir. Eles criam condições para que "os indivíduos só interajam com textos" (AUGÉ, 1994, p. 89) A constante presença de textos, placas e informativos presentes nos "não-lugares" impedem ao viajante de contemplar a paisagem pela qual está passando.

\section{Vazios Urbanos}

Como "vazios urbanos" é um tema muito recente, pouco se escreveu sobre o assunto. Embora tenham sido discutidas na Trienal de Arquitetura de Lisboa em 2007 as causas e soluções apontadas para os vazios urbanos, estas questões estavam voltadas para o contexto europeu. Sendo assim, cabe uma análise mais detalhada dos conceitos e causas dos vazios urbanos adaptadas ao nosso contexto.

Vazio urbano, de modo geral, é um espaço desabitado na cidade. Vários lugares podem ser nomeados como tal, dependendo do ponto de vista. Ao analisar a cidade de uma vista aérea, os vazios urbanos são grandes parques, praças, grandes avenidas, rios, como, por exemplo, em Belo Horizonte: Av. Afonso Pena, Av. Antônio Carlos, Praça do Papa, Ribeirão Arrudas, Lagoa da Pampulha, Parque Municipal ou Mangabeiras. Tomando uma escala menor, a dos bairros, os vazios seriam as ruas, praças, lotes, grandes construções. Seriam áreas de menor adensamento que propiciam o vão, o vazio entre as edificações. Reduzindo a escala para a visão do pedestre, encontramos lotes vazios, edificações e construções abandonadas. De modo geral, os vazios são os espaços que de certa forma possibilitam a visualização do horizonte. São espaços entre os cheios que nos permitem concluir que a cidade não está parada, é algo mutável e com potencialidades de apropriação, modificação e crescimento.

\section{Resíduos Urbanos}

Outras áreas também consideradas como vazios são os "resíduos urbanos", espaços resultantes da urbanização descontínua e heterogênea das cidades. Ainda hoje nas grandes obras de "melhorias" no sistema viário da cidade, os projetos continuam a deixar esses "terrenos residuais" - uma espécie de sobra de terreno dentro da cidade, resultado da implantação, por exemplo, de retornos e viadutos. Na parte planejada de Belo Horizonte, o traçado reticular cortado por avenidas na diagonal resulta em quarteirões triangulares, pontas, sobras de terreno.

A cidade é composta por edificações, ruas, avenidas e outros elementos, cada qual com sua função. Ao andar pela cidade nos deparamos com áreas não edificadas, áreas residuais resultantes da construção de ruas, pontes, elevados e edificações. Essas áreas são os considerados "vazios urbanos", áreas que podem ser vegetadas, arborizadas ou deixadas ao descaso. Muitas dessas áreas são ocupadas por moradores de ruas, que se apropriam do espaço de modo a torná-las seu habitat. 


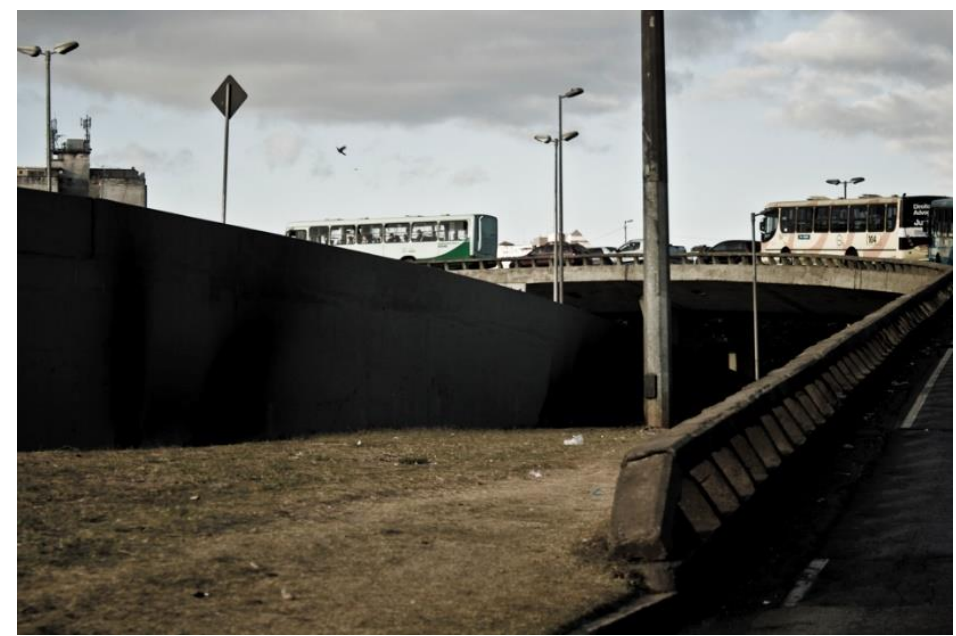

Fig. 4: Viaduto. Fonte: Coleção do autor

\section{Os vazios urbanos e seus arredores}

Vazios urbanos são áreas dentro do perímetro urbano que não são habitadas, áreas que por vários motivos não tiveram nenhum tipo de construção e quando edificadas não estão habitadas. Ocorre ausência de apropriação, seja ela o morar, o trabalhar ou mesmo o lazer. Esses vazios compõem a estética das cidades desde a sua formação, uma vez que o modelo de loteamento urbano brasileiro faz a divisão dos lotes sem a previsão imediata de construção. Com isso são construídas ruas, com toda infraestrutura necessária para tal (saneamento básico, iluminação, mobiliário), que permanecem durante anos sem uso por falta de construções ao redor.

As áreas que não são habitadas podem muitas vezes não ser notadas, dessa forma acabam por ficar ao acaso. O descaso vindo tanto do poder público como do proprietário do imóvel resulta na falta de condições básicas para transitar ou permanecer próximo a esses espaços. Costumam ser carentes de iluminação, bons tratos, mobiliários urbanos e, sobretudo limpeza. São áreas marginalizadas, onde há acúmulo de lixo, calçadas degradadas que impossibilitam o tráfego de pedestres e abrem espaço para a criminalidade. Esse abandono interfere muito na vida das pessoas ao redor. Por outro lado, um lote vazio repleto de vegetação é um meio para a cidade respirar, ou uma área onde a população tem potencial de apropriação, transformando-o em lugar, espaço de lazer por exemplo.

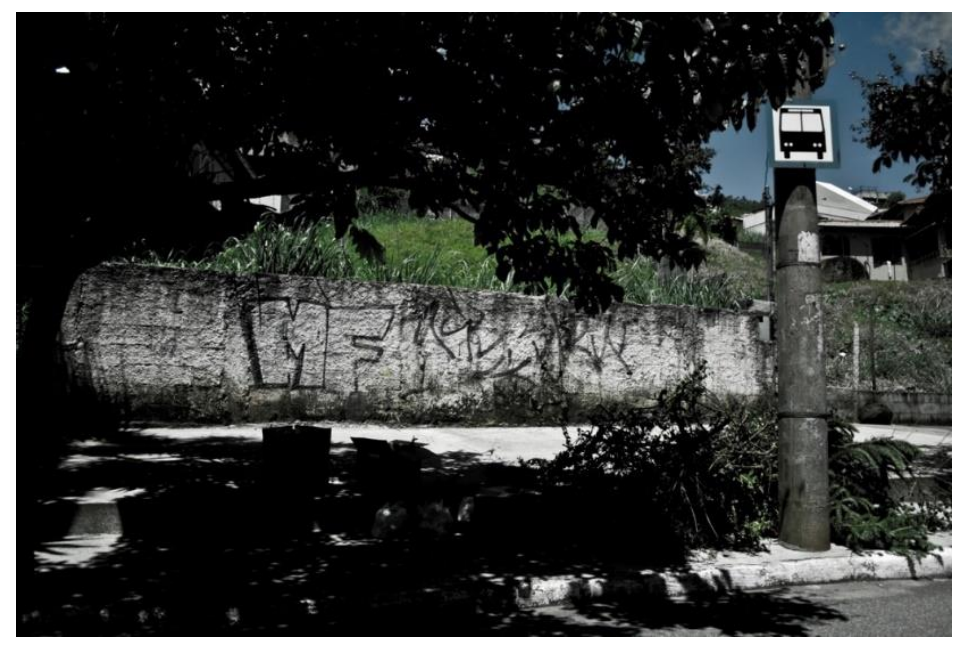

Fig. 5: Lote abandonado. Fonte: Coleção do autor 


\section{Projeção dos vazios}

Para muitos, o vazio é visto como um fator ruim, de degradação, e tem como objetivo a ocupação deste. $\mathrm{O}$ espaço desocupado é visto como um defeito físico da cidade, e para ele são propostas construções e habitações.

O arquiteto e filósofo Ignasi de Solà-Morales (2002) fala que os vazios “(...) são lugares obsoletos em que apenas certos valores residuais parecem manter-se apesar da completa desafetação da atividade da cidade.”. Fala também de a importância desses espaços serem improdutivos e fugir da tradicional urbanização. Contrariamente, outro arquiteto, Rem Koolhaas (2007), trata o vazio como um grande potencial. Fala da importância do vazio nas cidades, que com eles a cidade respira, um contraste entre o vazio e a parte mais densa da cidade.

Os curadores da Trienal de Arquitetura de Lisboa em 2007, que teve como tema "vazios urbanos" o definem como: "fenômenos de rarefação, indefinição ou ruptura urbana, são inúmeras vezes associados a novas realidades de colonização territorial ou a processos de marginalização, degradação e decadência física.". (<http://trienal.blogs.sapo.pt/326.html〉. Acesso em: 03/08/2010)

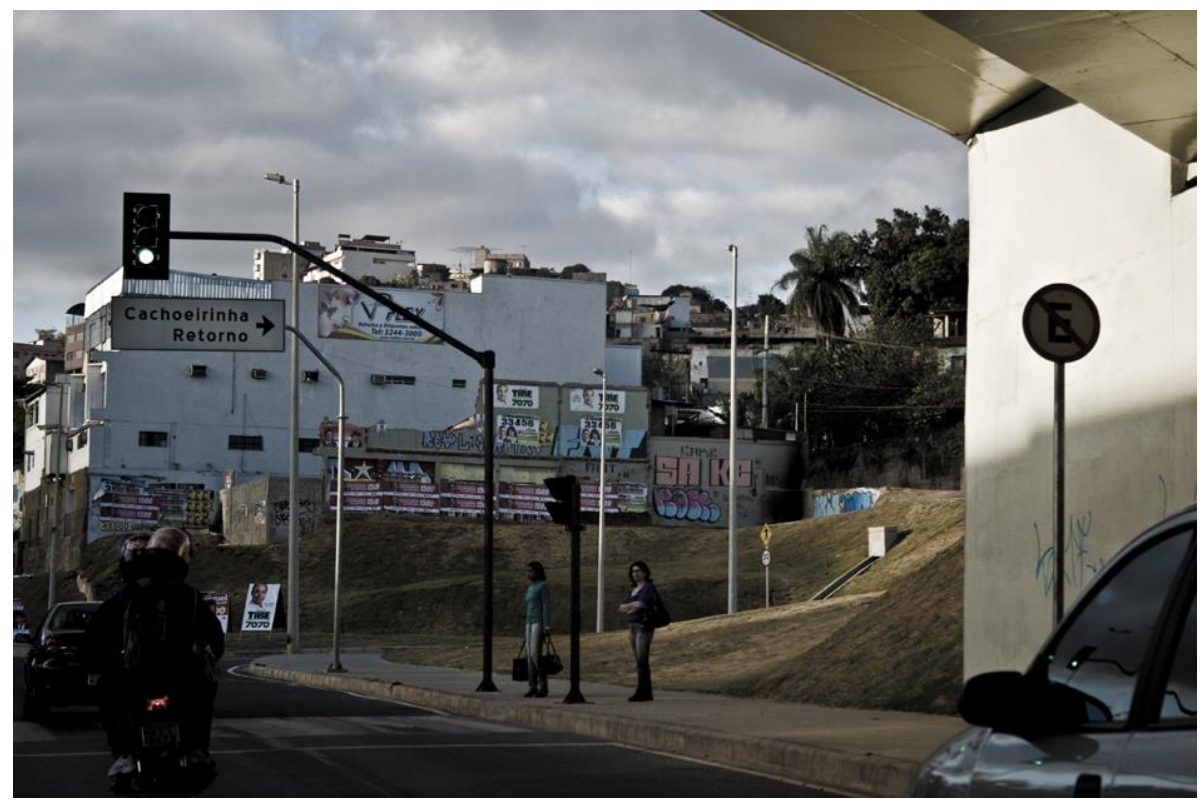

Fig. 6: Av. Presidente Antônio Carlos. Fonte: Coleção do autor

\section{Morfologia dos vazios urbanos}

A modernidade alterou muito a urbanização das cidades, o tráfego de carros e caminhões mudou o tamanho e a dinâmica das ruas, interferiu na vida dos pedestres e acarretou uma inversão da lógica - cidades complexas e casas simples. Hoje os condomínios nas cidades ao redor de Belo Horizonte, ou ainda que dentro do perímetro municipal, são as áreas mais valorizadas. O mercado passou a vender qualidade de vida como "ar puro", silêncio, calmaria, segurança, entre outros.

A força do mercado imobiliário tem ação direta na morfologia das cidades, uma vez que contribui para a especulação imobiliária. Os lotes ficam abandonados à espera de valorização gerando vazios urbanos. Em Belo Horizonte esses lotes são encontrados, em sua maioria, na zona suburbana, nos arredores da Av. do Contorno. 


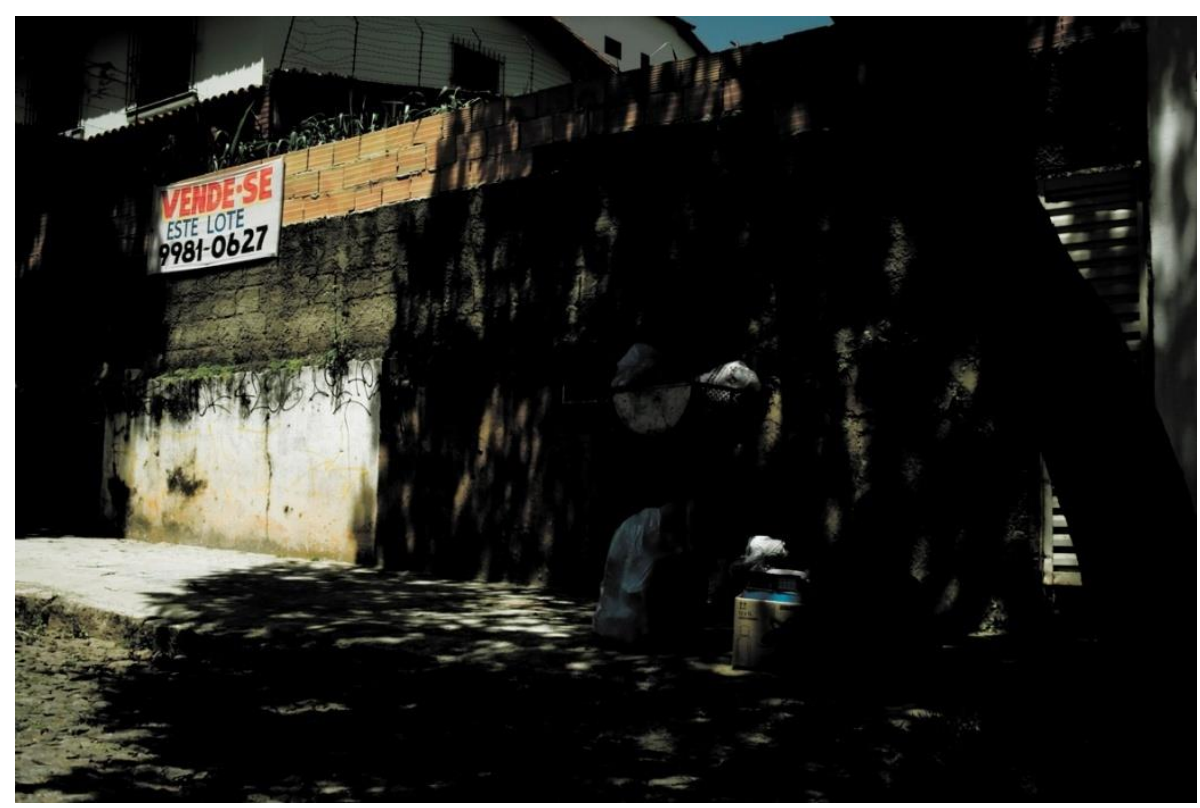

Fig. 7: Lote vago. Fonte: Coleção do autor

$\mathrm{Na}$ área denominada urbana por Aarão Reis, os vazios urbanos tomam aspectos diferentes. O centro sofre do abandono, da falta de identidade e apropriação. São edificações em péssimo estado de conservação, hoje invadidas ou abandonadas. Muitas dessas edificações são resultantes de processos judiciais, embargo de obras e falência de construtoras.

A história de Belo Horizonte se destaca pelo constante processo de verticalização;o cartão-postal típico é constituído de um cenário com construções. Com isso, parte dos vazios é de caráter efêmero, uma vez que o tempo de permanência de um vazio é o tempo da substituição de uma edificação por um prédio.

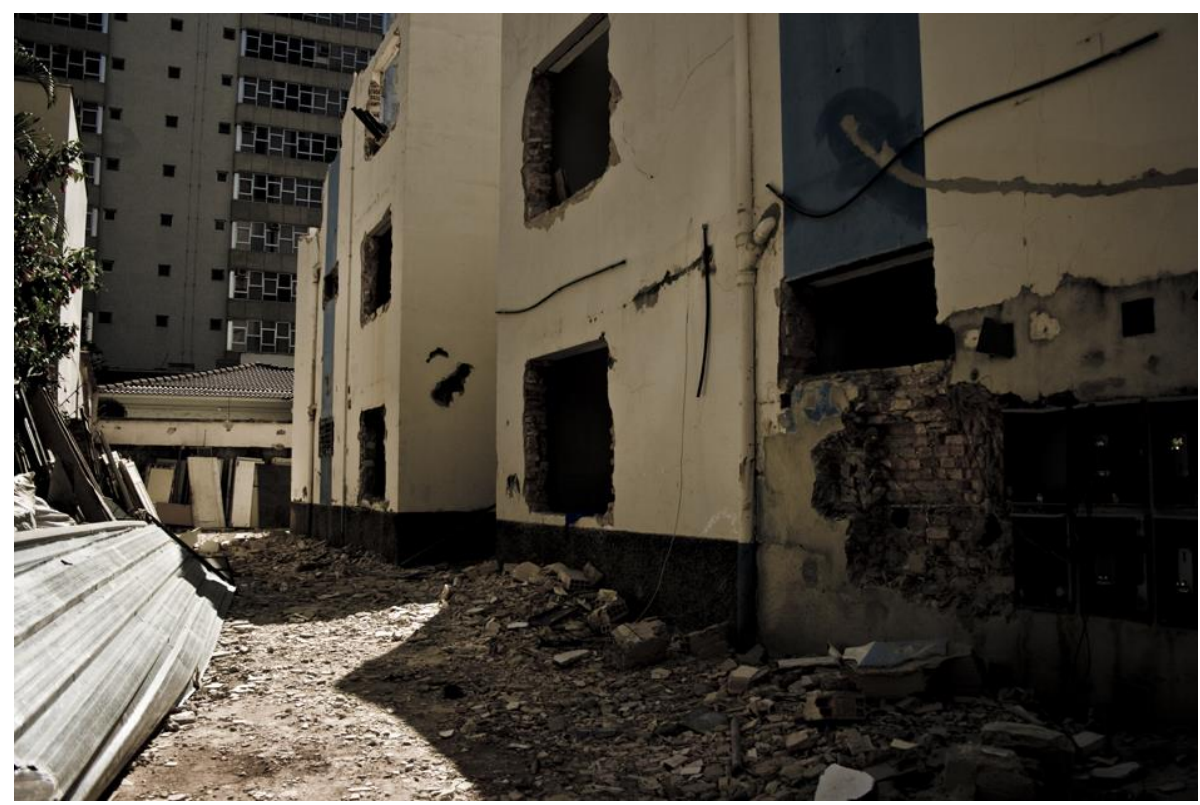

Fig. 8: Sem título. Fonte: Coleção do autor

A retomada da valorização do centro da cidade por iniciativa, sobretudo do governo, é vista por alguns como um fator positivo. Vários fatores irão determinar esta positividade ou não. Dentre eles, está um conceito muito debatido hoje, chamado "gentrificação". A 
gentrificação é resultado da valorização de um espaço por interferência, de iniciativa privado ou do governo, sem o devido tempo para a população se adaptar. O que ocorre é expulsão da população ocupante, geralmente de baixa renda (seja moradora ou frequentadora) do espaço por uma substituição de valores.

No intervalo entre o centro e os grandes condomínios situados nos arredores de Belo Horizonte, grande parte do trajeto é cortado por grandes avenidas que se adaptam entre favelas e bairros formais. Dentro dessa área é possível notar adensamentos como as favelas e conjuntos habitacionais. Apesar desse excesso, não é difícil encontrar terrenos de tamanhos razoáveis à espera de apropriação.

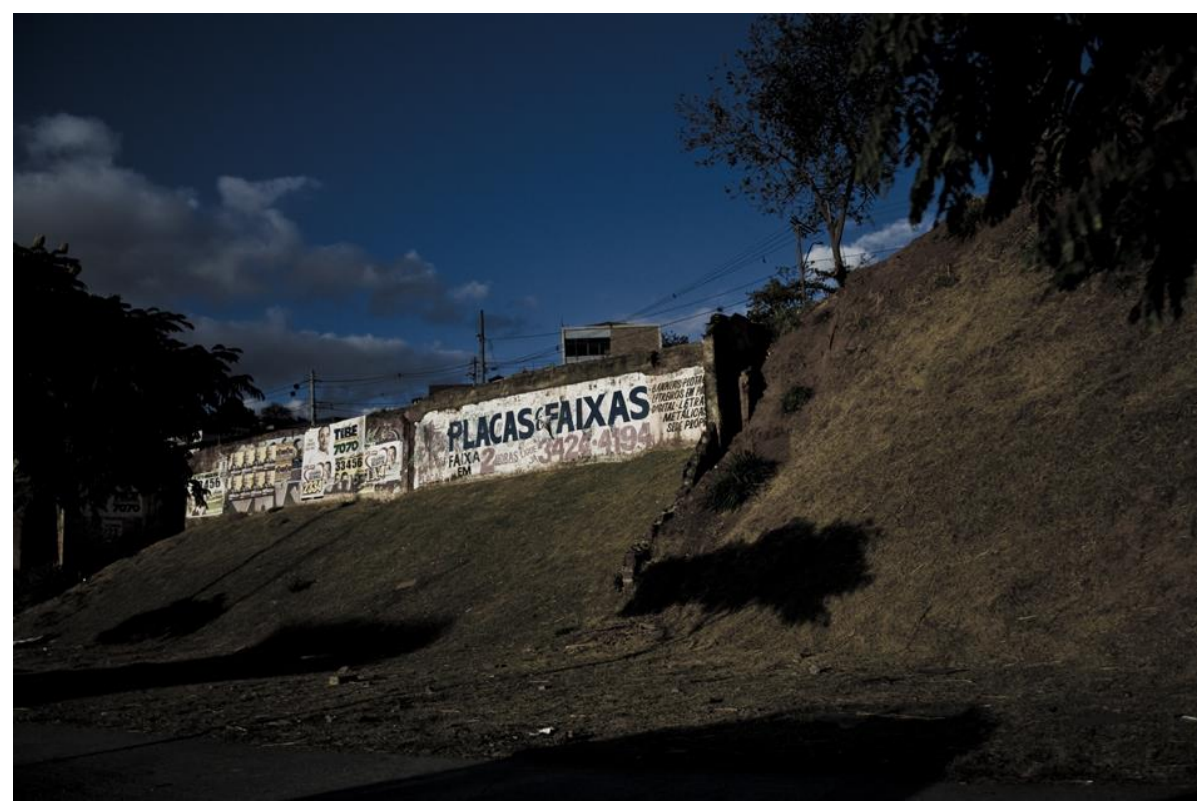

Fig. 9: Vazio. Fonte: Coleção do autor

\section{Fotografia urbana}

Em meio a cidade moderna o surgimento da fotografia gerou várias transformações, principalmente na forma com que as pessoas entendiam a imagem, um instrumento que transformou o modo de como as coisas são registradas e documentadas. Os documentos e registros existentes eram produzidos através de representações feitas por artistas, sejam elas pintura, desenho e gravura. Com isso a fotografia veio buscando seu lugar na sociedade moderna.

De acordo com o avanço das técnicas fotográficas as imagens eram produzidas com uma velocidade maior e com uma riqueza de detalhes que não caberia a outras formas de produção artística. A representação do artista passou a ser questionada, o desenho produzido foi perdendo lugar para uma imagem muito mais fiel a realidade. O registro feito pelas mãos imprecisas do artista cedeu lugar para o desenho da luz captado pela máquina, um registro a altura e de acordo com a mecanização corrente das cidades modernas. A fotografia é máquina, em vez de representar, ela tem a função de captar. Captar forças, movimentos, intensidades, densidades, visíveis ou não. Não é sua função representar o real e sim, produzir e reproduzir o que é passível de ser visível. 


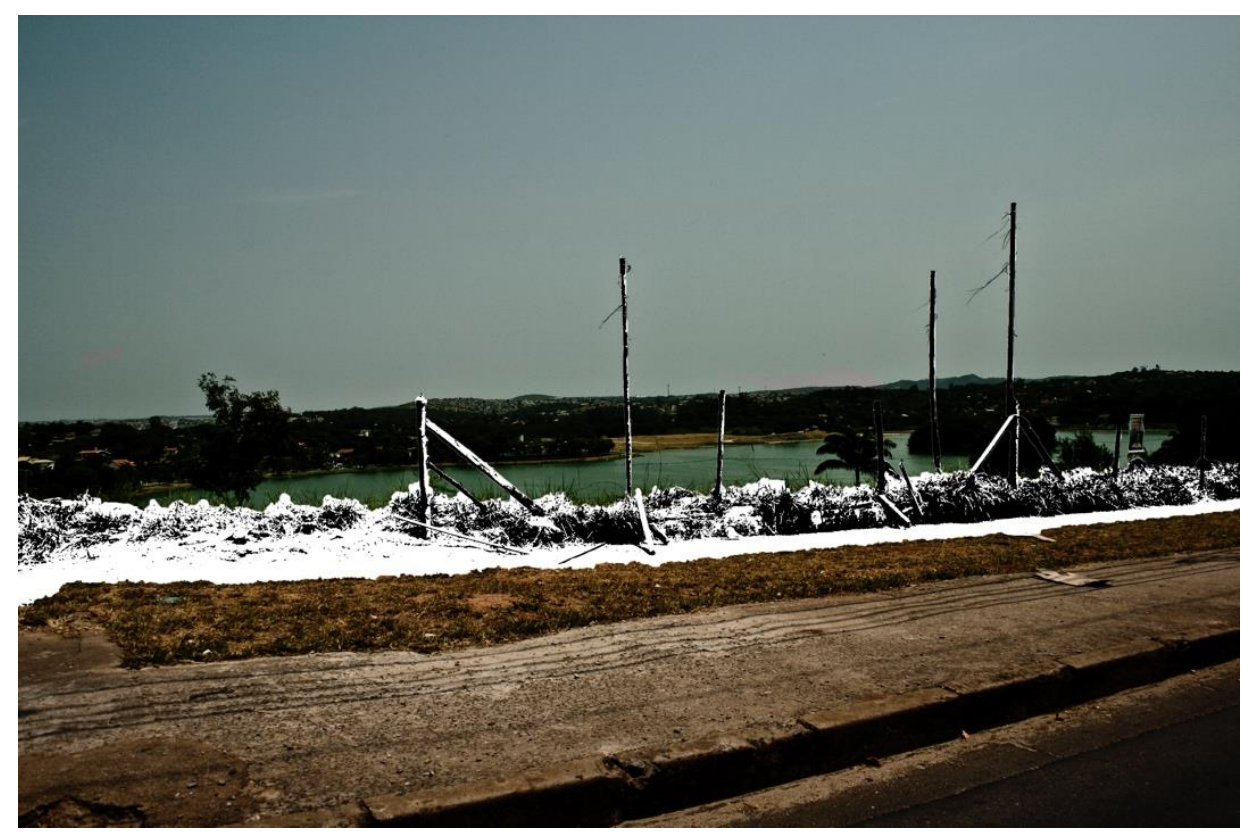

Fig. 10: Sem título. Fonte: Coleção do autor

Os primeiros registros feitos pelo daguerreótipo, primeiro processo fotográfico, são imagens dos telhados de Paris. Desde seu surgimento a fotografia tem um caráter urbano intrínseco, pois retrata, com precisão, motivos como: cidades, arquitetura, monumentos, pessoas, acontecimentos, etc. "Ultrapassando as capacidades do olho, essa precisão está mais adaptada às formas urbanas (arestas afiadas, ângulos retos, ou linhas retas, etc.) do que às formas difusas dos campos e das florestas do interior.”. (ROUILLÉ, 2009, p. 43)

A fotografia convém da modernidade como produto e instrumento, uma vez que participa ativamente da urbanização e expansão das cidades modernas. Ao registrar as transformações ocorridas no perímetro urbano, as imagens resultantes servem como documentação e registro das constantes mutações. Mutações como o aumento do ritmo da vida social, mecanização e industrialização transformaram a sociedade, e acabou por gerar uma necessidade de precisão, quando o instante passa a ter maior importância. A fotografia se reafirma urbana pois ela capta o instante, um processo cronometrado.

(...) a partir da metade do século XIX, a fotografia introduz, nas imagens, valores análogos àqueles que, por toda parte, estão transformando a vida e a sensibilidade dos habitantes das grandes cidades industriais. Um conjunto de convergências, de simultaneidade e de solidariedades silenciosas aproxima a dinâmica industrial, o desenvolvimento das cidades, a transformação dos modos de vida e das sensibilidades, os gostos artísticos, e a fotografia. (SONTAG, 2007, p. 45)

Mas a fotografia rejeitou muito tempo a urbanização, ficando à mercê de um cenário de poder, registrando monumentos e obras arquitetônicas. Durante muito tempo se fotografou um cenário sem homens, uma cidade na qual reinava um enorme vazio. Mas com a transformação urbana e industrial isso começa a mudar. O Fotógrafo Eugene Atget começa a registrar uma Paris diferente, uma cidade que está se transformando, ele registra o que está prestes a ser substituído: edificações, portas, janelas. Ainda uma fotografia sem transeuntes. "O fotógrafo é 
uma versão armada do solitário caminhante que perscruta, persegue, percorre o inferno urbano, o errante voyeurístico que descobre a cidade como uma paisagem de extremos voluptuosos.". 5

Foi com o surgimento da reportagem e a imprensa ilustrada que a fotografia foi de encontro com a população. A partir de então, os fotógrafos buscavam notícias, acidentes, assassinatos, a imprensa sensacionalista queria um diário policial. Com isso houve um deslocamento do objeto fotografado, passando de edificações para a cidades e seus habitantes.

Em meio a esses acontecimentos, o fotógrafo Weegee fotografa a parte obscura da sociedade, a noite de Paris, uma noite repleta de crimes, assassinatos, etc. Por outro lado, o olhar do flâneur de Baudelaire, o fotógrafo Brassai, mostra uma cidade tomada pelas sombras, uma fotografia cheia de poesia, um cenário de solidão.

O flâneur não se sente atraído pelas realidades oficiais da cidade, mas sim por seus recantos escuros e sórdidos, suas populações abandonadas - uma realidade marginal por trás da fachada da vida burguesa que o fotógrafo "captura", como um detetive captura um criminoso. (SONTAG, 2007, p. 70)

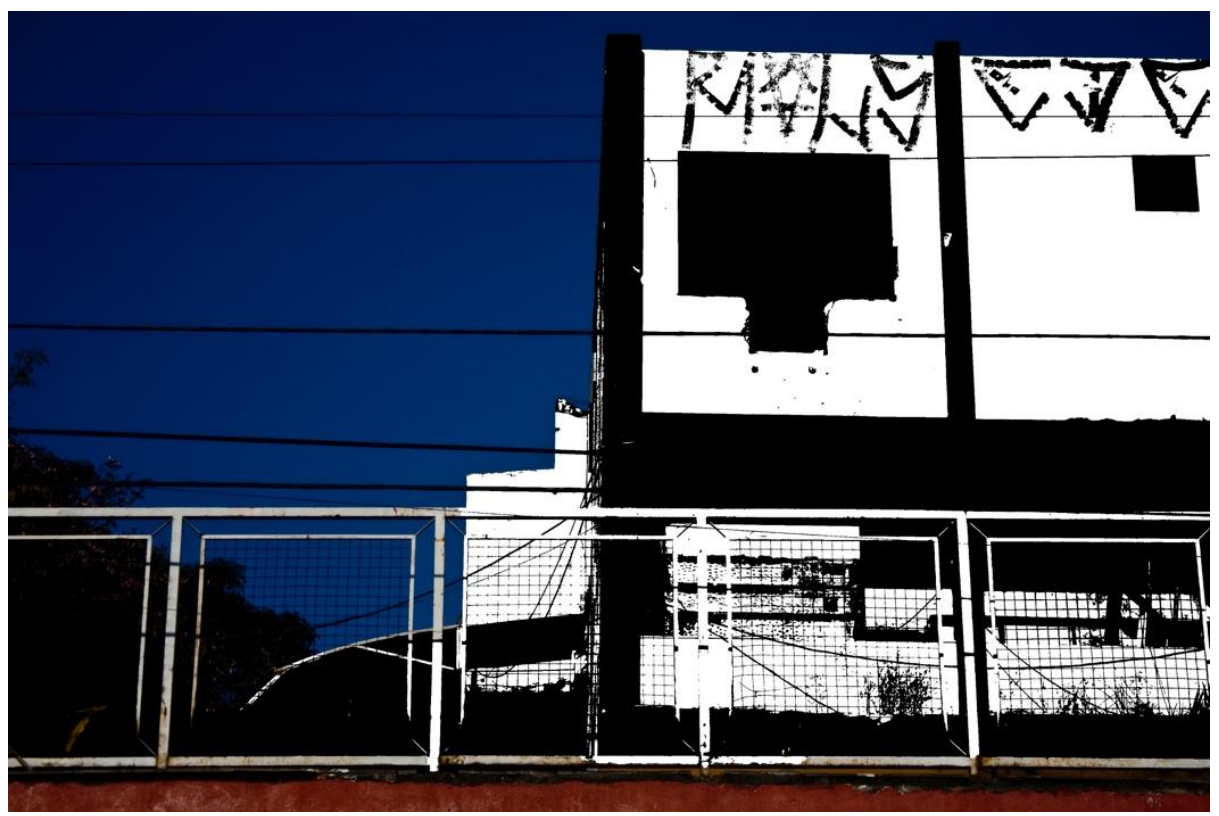

Fig. 11: Sem título. Fonte: Coleção do autor

A fotografia-documento, essa surgida com a reportagem, perpetuou por mais de um século. É uma imagem-documento dominante, que só perdeu espaço para o surgimento de imagens ao vivo. Com essa monopolização e o questionamento pela fotografia-expressão, esta "não recusa totalmente a finalidade documental e propõe outras vias, aparentemente indiretas, de acesso às coisas, aos fatos, aos acontecimentos.”. (ROULLÉ, 2009, p. 161)

As paisagens transparecem no renascimento, com o surgimento da perspectiva e são representadas pelos pintores. Posteriormente foi adotada pelos primeiros fotógrafos, muito usada pela fotografia-documento e depois deixada de lado pela fotografia-expressão, pois o objetivo não era mostrar a vida como é e sim, buscar novas maneiras de enxergar as paisagens.

O Fotógrafo Robert Frank foi o que melhor aproveitou essa nova estética iniciada com a fotografia-expressão. Com apoio financeiro de uma fundação, pôde percorrer boa parte dos Estados Unidos. Frank vai confirmar através de sua fotografia o aparecimento de uma nova

\footnotetext{
${ }^{5}$ SONTAG, 2007, p. 70
} 
perspectiva, a importância de uma subjetividade ao invés de uma imagem surgida de um único ponto. "Resumindo, vai transformar os modos de ver e as maneiras de mostrar que prevaleceram, até então, com a fotografia-documento.”. ROULLÉ, 2009, p. 170)

Vários fatores influenciaram Frank na concepção da sua fotografia, a começar da escolha da máquina fotográfica, uma máquina leve, muito utilizada pelos jornalistas, que proporcionou mobilidade. O recurso financeiro obtido através da bolsa foi um fator muito importante. Devido à bolsa, Frank pôde viajar e teve liberdade para fotografar sem restrições, a seu gosto e modo. Essa liberdade fez com que o fotografo fizesse seu percurso sem destino nenhum. "É um território do nonsense, assim como uma zona de acasos, de encontros fortuitos e efêmeros, de atenção aos espaços, às coisas e aos mínimos acontecimentos do cotidiano. É um espaço do vazio." (ROULLÉ, 2009, p. 171).

Robert Frank buscava sempre a expressão em suas fotografias, seja através de defeitos contidos nos negativos, um enquadramento inesperado, imagens desfocadas, imagens granuladas, imagens que não eram aceitas na fotografia-documento.

Se as fotos de Frank rompem com a estética documental é porque elas não representam (alguma coisa que foi), mas apresentam (alguma coisa que aconteceu); é porque não remetem às coisas, mas aos acontecimentos; é porque elas quebram a lógica binária da aderência direta com as coisas pela afirmação de uma individualidade.”. (ROULLÉ, 2009, p. 173)

A Missão Datar foi um conjunto de fotógrafos contratados para registrar uma nova paisagem francesa. Era um novo olhar de "fotógrafos artistas" ou daqueles que tinham como trabalho e pesquisa uma estética diferenciada da fotografia-documento, profissionais ligados ao procedimento expressivo. Isso foi reforçado devido a crise que a fotografia-documento estava inserida, crise esta que ocorreu devido a necessidade de uma fotografia mais sensível, de pontos de vista variados. Não era mais uma fotografia ligada à impressão. “(...) o programa da fotografia-expressão, segundo o qual o documento requer uma escrita, um formato plenamente assumido por um autor.” (ROULLÉ, 2009, p. 163).

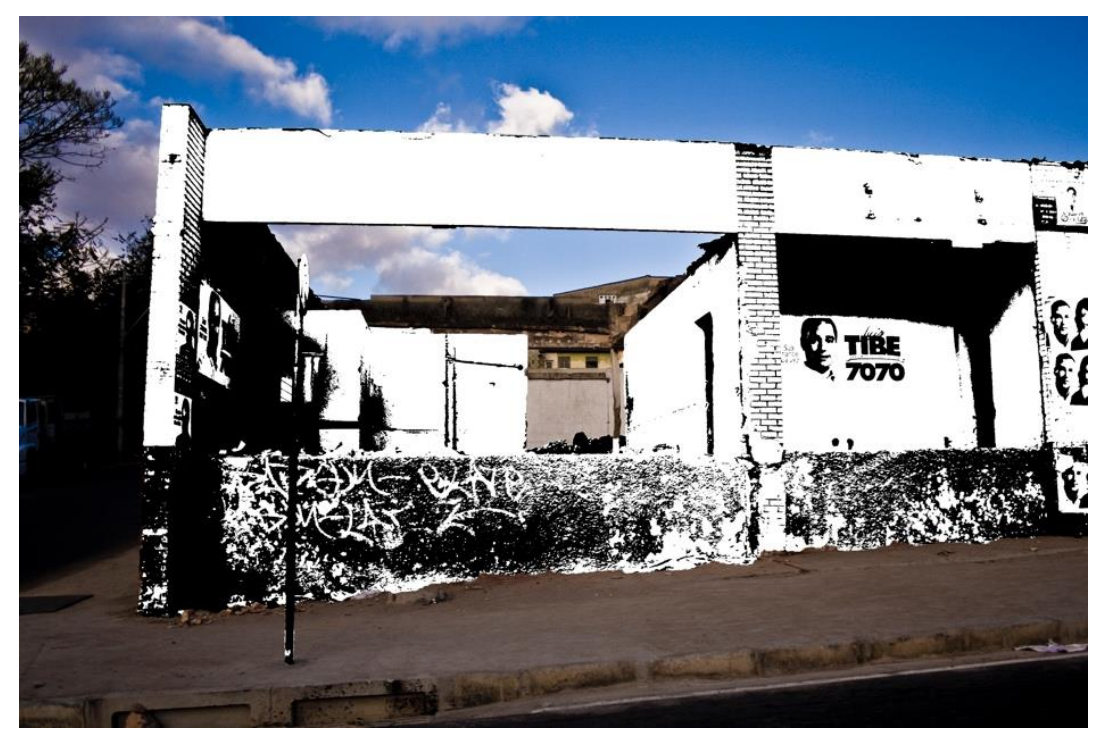

Fig. 13: Sem título. Fonte: Coleção do autor

Dos participantes da Datar, o fotógrafo T om Drahos se destaca por apresentar aspectos bem diferenciados em sua fotografia. Ele trabalha a monocromia, afastando assim a fotografia do real. 
Drahos não tem como objetivo o registro fiel da paisagem e sim uma imagem que busca a representação de forma diferenciada. Em vez de mostrar o que exatamente fotografou, ele trabalha mais com imagens imprecisas, subjetivas. A Missão Datar transformou a forma com que se compreendia a fotografia, abrindo espaço para uma produção mais livre; uma fotografia-expressão que tivesse enraizado a importância do autor, a busca do fotografo por uma estética diferenciada.

Essa afirmação de uma individualização abre procedência para uma busca cada vez mais valorizada da fotografia autoral, uma fotografia que busca além da expressividade uma proposta artística. "O principal projeto da fotografia dos artistas não é reproduzir o visível, mas tornar visível alguma coisa do mundo, alguma coisa que não é, necessariamente, da ordem do visível." (ROULLÉ, 2009, p. 287).

\section{Conclusão}

É possível uma avaliação do histórico da construção da cidade de Belo Horizonte, a qual desde o seu projeto inicial cria possibilidades para o desenvolvimento de vazios interstícios. $\mathrm{Na}$ chamada zona suburbana do projeto de Aarão Reis, o modelo de loteamento fez a divisão dos lotes sem a previsão imediata de construção, enquanto que na zona urbana ocorrem hoje os processos de abandono, da falta de identidade e de apropriação, e verticalização. São, em grande parte, edificações degradadas, em tempo de modificações, hoje invadidas ou abandonadas.

Quando pensamos os vazios urbanos não apenas pela ausência de apropriação, nos deparamos com a ótica do não-lugar. Ambos os termos podem ser materializados dentro do contexto urbano. Através desses espaços, é possível uma fotografia-expressão não apenas da forma estática, mas de tudo aquilo que esse espaço carrega de subjetividade, de negação, do não olhar e omissão da população. Podem compor uma estética diferenciada, de choque, ou mesmo instigar o olhar de possibilidade, um espaço potencial para novas formas de intervenção, a constante mutação da cidade.

Através do estudo da história da fotografia pode-se afirmar que sua existência está diretamente relacionada ao espaço urbano. Muitas vezes, a fotografia se fez necessária para o registro da arquitetura, ausente de qualquer transformação ou presença de pessoas, em outras foi a busca incessante pelos acontecimentos, notícias. A fotografia-expressão foi adquirindo seu espaço com a necessidade de uma fotografia mais livre, que ressaltasse a posição do autor.

O vazio sempre foi tema registrado pela fotografia, essa busca pelo imperfeito e pelo caos é de suma importância, pois chamou atenção para situações corriqueiras, presentes no cotidiano e, muitas vezes, não percebidas. O flaneur ainda percorre as ruas das cidades registrando transformações urbanas e sociais.

\section{Referências}

AUGÉ, Marc. Não-lugares: Introdução a uma Antropologia da Super modernidade. Campinas: Papirus, 1994.

BENJAMIN, Walter. A Obra de Arte na Época de suas Técnicas de Reprodução. In: Textos Escolhidos / Walter Benjamin, Max Hokheimer, Theodor W. Adorno, Jürgen Habermas. São Paulo: Abril Cultural, 1983.

BOURRIAUD, Nicolas. Estética Relacional. São Paulo: Martins, 2009.

Pós-produção: como a arte reprograma o mundo contemporâneo. São Paulo: Martins, 2009. 
CAUQUELIN, Anne. Arte Contemporânea: uma introdução. São Paulo: Martins, 2005.

KOOLHAAS, Rem. La ciudad genérica. Barcelona: Editora Gustavo Gili, 2007. . Conversa com estudantes. Barcelona: Editora Gustavo Gili, 2007.

MOLINA Diego, MONTOYA Alberto. Vazios Urbanos = Urban Voids. Lisboa: Editora Caleidoscópio, 2007.

PEIXOTO, Nelson Brissac. Paisagens urbanas. São Paulo: Senac, 1996.

RUILLÉ, André. A fotografia entre documento e arte contemporânea. São Paulo: Editora Senac, 2009.

SOLÀ-MORALES, Ignase de. “Terrain Vague”. In: . Territorios. Barcelona: Editorial Gustavo Gili, 2002

SONTAG, Susan. Ensaios Sobre a Fotografia. Rio de Janeiro: Arbor, 1981.

TEIXEIRA, Carlos M. Em obras: História do vazio em Belo horizonte. São Paulo, Cosac \& Naify. 1999.

\section{Documentos eletrônicos}

Ver: <http://trienal.blogs.sapo.pt/326.html >. (Acesso em: 03/08/2010, às 15hs)

Ver: <http://maps.google.com.br/>. (Acesso em: 05/04/2010, às 10hs) 